\title{
Characterization of date palm frond as a fuel for thermal conversion processes
}

\author{
Hussain Sadig ${ }^{1}$, Shaharin Anwar Sulaiman ${ }^{2,}$, Mohamad Nazmi Zaidi Moni ${ }^{2}$ and Lanisha Devi Anbealagan ${ }^{2}$ \\ ${ }^{1}$ Department of Mechanical Engineering, Faculty of Engineeting and Technology, Nile Valley University, P.O Box 26, \\ Atbara, Sudan \\ ${ }^{2}$ Hybrid Energy Systems MOR, Universiti Teknologi PETRONAS, 32610 Seri Iskandar, Perak Darul Ridzuan, Malaysia
}

\begin{abstract}
Date palm fronds (DPF) have similar physical appearances to those of oil palm fronds and coconut palm fronds, which have been reported as having good potential as a source of energy through thermochemical conversion of biomass. However, nearly no report has been found pertaining to thermochemical properties of DPF. Hence, it has remained unclear whether DPF can become suitable feedstock for power generation. This study investigated the characteristics of DPF as a potential solid fuel for heat and power generation through various thermal conversion processes. DPF samples from selected sites in Sudan and Saudi Arabia were tested. The ultimate and proximate analyses and the calorific value of DPF were measured, and the results were compared with low to medium-rank coals and other common biomass materials. The calorific value range for DPF samples was found to be between 16.2 to $16.9 \mathrm{MJ} / \mathrm{kg}$. The ultimate analysis of DPF samples revealed that more than $75 \%$ of their mass was composed of volatile materials, while the ash content in all samples was found to be less than $15 \%$. The range of elementary carbon, hydrogen, nitrogen, sulfur and oxygen in DPF samples was found to be typical to that in biomass. The thermal decomposition trends the samples indicated the high reactivity of DPF with rising temperatures due to high holocellulose content. No distinctive differences in test results were observed between samples from Saudi Arabia and Northern Sudan. Overall, it was found that all DPF samples used in this study fulfilled the typical requirements for development and utilization as a solid fuel.
\end{abstract}

\section{Introduction}

Date is the fruit of date palm (Phoenix dactylifera L.). As one of the oldest known fruit crops, date has been cultivated in North Africa and the Middle East for at least 5000 years, with the earliest record of date culture discovered from the Mesopotamian region of Iraq dating back to $3000 \mathrm{BC}^{1}$. Date cultivation has not only great spiritual and cultural significance but also became a sacred symbol especially to the early population of the arid regions in Middle East and North Africa. In today's world, date industry enjoys a worldwide courtesy due to the growing global demands. With reference to the online database maintained by the Food and Agriculture Organization of the United Nations (FAO), there are currently 40 countries in the world that cultivate date palms in a large scale for date trade. Most of these countries are located in the Middle East, while others are scattered at other parts of the globe. In 2014, around 7.76 million tons of dates were produced from over 1.14 million hectares of date palm plantation worldwide. The Middle Eastern countries contributed to around $40 \%$ of the total harvested area, with about $30 \%$ of the global production ${ }^{2}$.Date palm frond (DPF) is the branching part of a date palm tree and is a waste residue of the date fruit industry. DPF is produced during pruning activity, along with other wastes such as foliar and thorns ${ }^{3}$. On average, a date palm tree sheds $14-20 \mathrm{~kg}$ of dry DPF annually, replacing with 12-15 new fronds ${ }^{4-6}$. Given that 1.14 million hectares of land were cultivated with date palm in 2014 and assuming an average density of 100-150 trees/ha, it is estimated that around 1.6 to 3.4 million tons of dry DPF are available each year ${ }^{7}$. From morphological perspective, DPF is quite similar to coconut frond (CF) and oil palm frond (OPF), and therefore is anticipated to have potentials as a source of power through thermochemical conversion process. However, little work has been done in evaluating the feasibility of utilizing DPF as a solid fuel, and thus a study is required before one can embark into power generation using DPF.

Corresponding author: shaharin@utp.edu.my 
This paper examines the fuel properties of several samples of DPF collected from the North African and Middle Eastern regions for various thermal conversion process such as pyrolysis, torrefaction, gasification and as well as for general incineration purposes.

\section{Methodology}

Several dry DPF samples from Medina (Rothanah \& Ajwah varieties) and Jeddah (Jeddah \& Sukkari varieties) of Saudi Arabia and from Atbara, Northern Sudan (Mishriq variety) were received with removed leaflets via air courier. The samples were individually prepared to undergo three essential tests to evaluate their fuel properties: ultimate analysis, proximate analysis and calorific value analysis. Fig. 1 shows the as-received and the ground DPF samples.

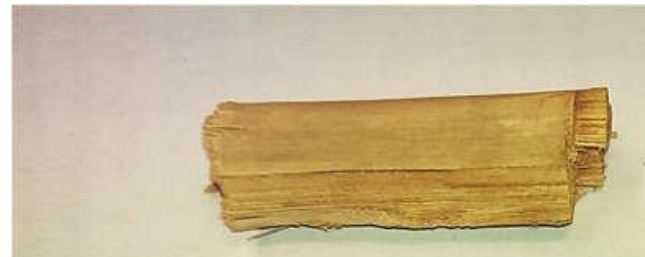

(a)

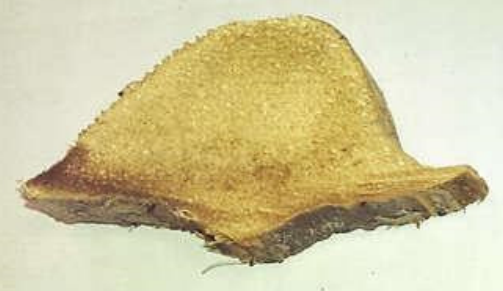

(c)

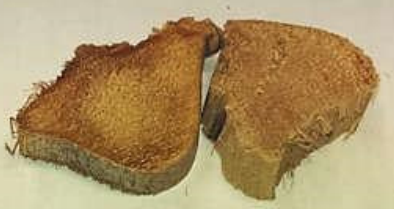

(b)

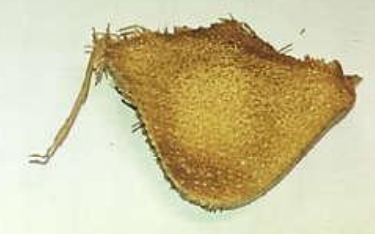

(d)

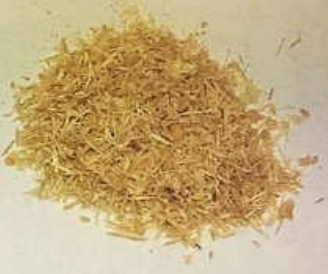

(e)

. As-received and ground DPF samples: (a) Mishriq variety, (b) Sukkari variety, (c) Jeddah variety, (d) Medina variety and (e) Rothanah variety (ground)

\subsection{Sample preparation}

Upon delivery, all DPF samples were dried in a convection oven at $105 \pm 0.5^{\circ} \mathrm{C}$ for 24 hours to remove remaining moisture and then stored in separated and labelled airtight containers. Around 50g of each sample were ground and sieved to obtain particles of $250 \mu \mathrm{m}$ in apparent size for calorific value measurement and proximate and ultimate analyses. The sieved samples were stored in labelled airtight plastic containers and sent for analyses.

\subsection{Calorific value}

Calorific value (or heating value) is the amount of energy contained in a fuel and is determined by measuring the amount of heat produced by the complete combustion of a known quantity of it. The calorific value for each sample was determined using an IKA C-6000 isoperibol calorimeter with reference to ASTM D-5865-13 standard, and is expressed as the gross calorific value. Around 2 to $4 \mathrm{mg}$ of sample was placed in the bomb vessel for calorimetric evaluation, which was conducted automatically by the device. 


\subsection{Proximate analysis}

The proximate analysis reveals the amount of moisture, volatile matter, fixed carbon and ash content in a fuel. The proximate analysis of DPF samples was conducted using Pyris 1 TGA thermogravimetric analyzer by PerkinElmer with reference to ASTM E1131-08 standard test method. Each ground sample with a known mass was subjected to heating up to $850^{\circ} \mathrm{C}$ in an inert gas environment and then in oxidant gas as the temperature rose to $900^{\circ} \mathrm{C}$. The $\mathrm{TGA}$ and derivative TGA (DTGA) trend generated by the test equipment for each sample was then examined for peaks to determine the amount of volatile matter, fixed carbon and ash based on mass loss, as well as the temperature peaks to determine the devolatilization stages during thermal degradation of DPF.

\subsection{Ultimate analysis}

The ultimate analysis is vital in assessing the elemental components in a biomass material in terms of carbon, hydrogen, nitrogen, sulfur and oxygen with regards to its suitability as a fuel. Otherwise known as the CHNS test, the ultimate analysis of the DPF samples was carried out using 2400 CHNS/O Series II System by PerkinElmer where the elementary carbon, hydrogen, nitrogen and sulfur components in the samples were measured by weight percentage. The oxygen content was determined by difference.

\section{Results}

\subsection{Calorific value}

Calorific value is the amount of energy contained in a specific quantity of fuel. Generally, the higher the calorific value of a fuel, the more energy will be released during its combustion. For this reason, fuel with high calorific value is more desirable for thermal conversion processes ${ }^{8}$. The calorific value for each of the DPF variety is shown in Table 1 , along with other common biomasses and coals. As a baseline, the range of calorific value of biomass materials is typically between 15 to $20 \mathrm{MJ} / \mathrm{kg}$, close to that of low rank coal such as peat and lignite. All DPF samples showed calorific value range of between 16.2 to $16.9 \mathrm{MJ} / \mathrm{kg}$. The highest calorific values were obtained from the Jeddah and Sukkari varieties while the lowest was from Rothanah variety, although with no apparent difference.

Table 1. Calorific values of DPF samples and selected types of coal and biomass

\begin{tabular}{|c|c|c|}
\hline Type & Sample & CV (MJ/kg) \\
\hline \multirow{7}{*}{ DPF } & Rothanah & 16.23 \\
\hline & Jeddah & 16.87 \\
\hline & Sukkari & 16.86 \\
\hline & Ajwah & 16.52 \\
\hline & Mishriq & 16.62 \\
\hline & Sukkari, base $^{9}$ & 15.47 \\
\hline & Sukkari, midrib $^{9}$ & 17.57 \\
\hline \multirow{3}{*}{ Coal } & Peat $^{11}$ & 14.00 \\
\hline & Lignite coal $^{12,13}$ & 16.30 \\
\hline & Bituminous coal $^{12,13}$ & 23.25 \\
\hline \multirow{12}{*}{ Biomass } & Corn stover ${ }^{13}$ & 17.65 \\
\hline & Walnut shell ${ }^{13}$ & 20.18 \\
\hline & Wheat straw $^{13}$ & 16.71 \\
\hline & Cotton stalk $^{13}$ & 18.26 \\
\hline & Coconut frond $^{14}$ & 21.17 \\
\hline & Coconut shell ${ }^{14}$ & 21.17 \\
\hline & Palm kernel shell ${ }^{14}$ & 20.40 \\
\hline & Empty fruit bunch ${ }^{14}$ & 18.60 \\
\hline & Oil palm frond ${ }^{14}$ & 15.59 \\
\hline & Sugarcane bagasse $\mathrm{e}^{14}$ & 15.25 \\
\hline & Rice husk $^{14}$ & 14.79 \\
\hline & Sawdust $^{14}$ & 18.19 \\
\hline
\end{tabular}




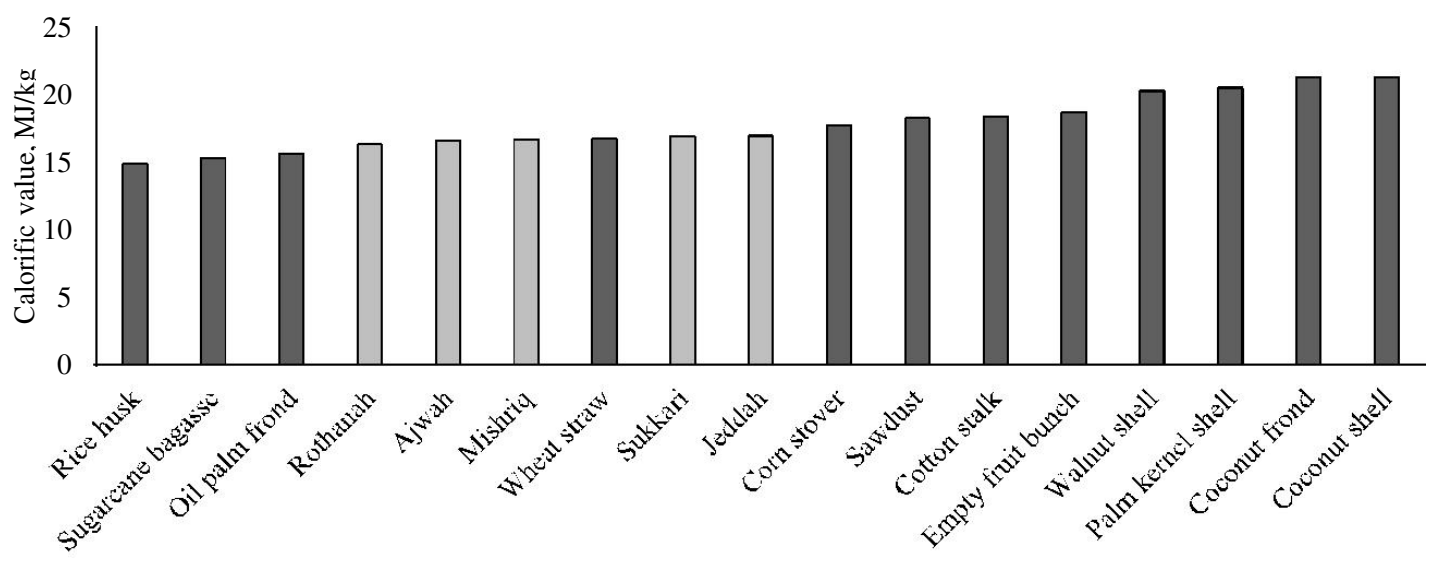

Biomass types

Fig. 2. Comparison of calorific value in DPF and selected biomass types

The calorific value of DPM samples were also verified with those from the work of Nasser et al, where the values were found to be in agreement with the reported figures ${ }^{9}$. The comparatively lower calorific values of DPF may be due to its low lignin content, as also revealed by Nasser et al in their work. Lignin is a natural polymeric fiber in plant matter that does not only contain the highest amount of energy but is also the hardest to thermallydecompose ${ }^{10}$. Compared to all parts of a date palm tree (coir, trunk, fruit stalk, empty fruit bunch and stone), DPF have the lowest content of lignin of around $25-26 \%$ by weight ${ }^{9}$. The calorific value of DPM samples was observed to be comparable with that of other biomass. All DPM samples were found to have lower calorific values compared to coconut frond, but nevertheless were higher than that of oil palm frond, as shown in Fig. 2. The calorific value of DPM samples was also found to be nearly similar to that of peat and lignite, thus confirming their potentials as solid fuels for home and industrial applications in terms of calorific value. Nevertheless, despite having comparatively lower calorific values than wood and several other biomasses, DPF is considered still suitable as a solid fuel for heat and power generation via thermal conversion processes.

\subsection{Ultimate analysis}

The ultimate analysis results for all DPF samples tested in this study are shown in Table 2. The range of carbon, hydrogen and oxygen in DPF was considered typical for biomass materials. The elemental carbon content in all DPF samples varied slightly with not so much differences. The same observation was made on hydrogen content, where its content was found to be between 5-6\% in all samples, and was comparable with that in the selected types of coal and biomass.

The amount of oxygen in all DPF samples was found to be above $51 \%$ and was considerably higher than that in coal and most biomasses, indicating the comparatively smaller amount of stoichiometric air requirement for DPF combustion. The amount of nitrogen was highest in Rothanah and lowest in Sukkari and Ajwah varieties. The nitrogen content in all samples was found to be higher than that in peat and lignite coal, and was almost as much as in bituminous coal. The same observation was made in comparison to the DPF samples analyzed by Nasser et al and to all the featured common biomasses. Nitrogen content in fuel tends to produce oxides of nitrogen (NOx), a type of toxic and undesirable combustion byproduct ${ }^{15}$. The sulfur content in all DPF samples was also found to be higher than that in most biomasses, and was within the range of that in low to medium rank coals. In comparison to the DPF samples from other work, relatively low amount of nitrogen and sulfur was reported. Along with oxides of sulfur (SOx), which is the byproduct of combustion due to existence of sulfur in fuel, NOx emission has to be regulated below the allowable discharge limit by legal requirement in most countries due to their contributions to climate change and greenhouse gas effects ${ }^{16}$. For this reason, the utilization of fuels with high nitrogen and/or sulfur may require additional downstream filtration to reduce NOx and SOx emissions, and may pose a considerable impact to operating expenditures, and may be avoided by thermal power producers ${ }^{17}$. If not properly addressed, this would be the greatest drawback of utilizing DPF as a fuel material. 
Table 2. Ultimate analysis of DPF samples and selected types of coal and biomass

\begin{tabular}{|c|c|c|c|c|c|c|}
\hline \multirow{2}{*}{ Type } & \multirow{2}{*}{ Sample } & \multicolumn{5}{|c|}{ Ultimate analysis (wt. \% db.) } \\
\hline & & $\mathrm{C}$ & $\mathrm{H}$ & $\mathrm{N}$ & $\mathrm{S}$ & $\mathrm{O}$ \\
\hline \multirow{7}{*}{$\mathrm{DPF}$} & Rothanah & 32.44 & 5.11 & 3.50 & 0.75 & 58.20 \\
\hline & Jeddah & 39.35 & 5.83 & 2.96 & 0.48 & 51.38 \\
\hline & Sukkari & 37.78 & 5.79 & 2.88 & 0.34 & 53.20 \\
\hline & Ajwah & 34.86 & 5.51 & 2.88 & 0.23 & 56.52 \\
\hline & Mishriq & 36.61 & 5.82 & 3.17 & 0.26 & 54.13 \\
\hline & Sukkari, base & 40.48 & 5.63 & 0.28 & 0.00 & 53.61 \\
\hline & Sukkari, midrib $^{9}$ & 45.65 & 5.95 & 0.27 & 0.00 & 48.13 \\
\hline \multirow{3}{*}{ Coal } & Peat $^{11}$ & 55.00 & 6.00 & 0.38 & 0.25 & 35.00 \\
\hline & Lignite coal $^{12,15}$ & 50.00 & 4.00 & 2.00 & 0.90 & 43.10 \\
\hline & Bituminous coal $^{1<, 15}$ & 68.00 & 4.00 & 3.00 & 0.90 & 24.10 \\
\hline \multirow{12}{*}{ Biomass } & Corn stover $^{13}$ & 43.65 & 5.56 & 0.61 & 0.01 & 50.17 \\
\hline & Walnut shell $^{15}$ & 49.98 & 5.71 & 0.21 & 0.01 & 44.09 \\
\hline & Wheat straw $^{13}$ & 43.20 & 5.00 & 0.61 & 0.11 & 51.08 \\
\hline & Cotton stalk $^{13}$ & 43.64 & 5.81 & 0.00 & 0.00 & 50.55 \\
\hline & Coconut frond $^{14}$ & 45.51 & 6.02 & 0.78 & 0.09 & 47.60 \\
\hline & Coconut shell $^{14}$ & 43.00 & 6.30 & 0.75 & 0.05 & 49.90 \\
\hline & Palm kernel shell ${ }^{14}$ & 49.65 & 6.13 & 0.41 & 0.48 & 43.33 \\
\hline & Empty fruit bunch $^{14}$ & 40.73 & 5.75 & 1.40 & 0.22 & 51.90 \\
\hline & Oil palm frond ${ }^{14}$ & 42.10 & 5.46 & 0.70 & 0.13 & 51.61 \\
\hline & Sugarcane bagasse $^{14}$ & 42.93 & 5.82 & 0.68 & 0.06 & 50.51 \\
\hline & Rice husk $^{14}$ & 38.74 & 5.83 & 0.55 & 0.06 & 54.82 \\
\hline & Sawdust $^{14}$ & 43.68 & 6.65 & 0.23 & 0.04 & 49.40 \\
\hline
\end{tabular}

Table 3. Proximate analysis of DPF samples and selected types of coal and biomass

\begin{tabular}{|c|c|c|c|c|}
\hline \multirow{2}{*}{ Type } & \multirow{2}{*}{ Sample } & \multicolumn{3}{|c|}{ Proximate analysis (wt. \% db.) } \\
\hline & & VM & $\mathrm{FC}$ & Ash \\
\hline \multirow{7}{*}{ DPF } & Rothanah & 76.25 & 17.5 & 6.25 \\
\hline & Jeddah & 88.61 & 9.28 & 2.11 \\
\hline & Sukkari & 86.38 & 10.12 & 3.50 \\
\hline & Ajwah & 86.10 & 6.26 & 7.63 \\
\hline & Mishriq & 80.33 & 12.68 & 6.99 \\
\hline & Sukkari, base & 76.56 & 9.81 & 13.63 \\
\hline & Sukkari, midrib $^{9}$ & 82.28 & 3.56 & 14.15 \\
\hline \multirow{3}{*}{ Coal } & Peat $^{11}$ & 65.00 & 26.50 & 8.50 \\
\hline & Lignite coal $^{12,15}$ & 34.41 & 48.39 & 17.20 \\
\hline & Bituminous coal $^{1<, \perp 5}$ & 18.69 & 61.86 & 19.63 \\
\hline \multirow{12}{*}{ Biomass } & Corn stover $^{13}$ & 75.17 & 19.25 & 5.58 \\
\hline & Walnut shell ${ }^{13}$ & 78.28 & 21.16 & 0.56 \\
\hline & Wheat straw $^{13}$ & 71.30 & 19.80 & 8.90 \\
\hline & Cotton stalk $^{13}$ & 70.89 & 22.43 & 6.68 \\
\hline & Coconut frond $^{14}$ & 80.24 & 13.06 & 6.70 \\
\hline & Coconut shell $^{14}$ & 78.00 & 19.48 & 5.52 \\
\hline & Palm kernel shell $^{14}$ & 81.03 & 14.87 & 4.10 \\
\hline & Empty fruit bunch ${ }^{14}$ & 84.61 & 9.89 & 5.50 \\
\hline & Oil palm frond ${ }^{14}$ & 83.19 & 12.91 & 1.26 \\
\hline & Sugarcane bagasse ${ }^{14}$ & 80.19 & 15.91 & 3.90 \\
\hline & Rice husk $^{14}$ & 59.97 & 18.03 & 22.00 \\
\hline & Sawdust $^{14}$ & 78.80 & 16.20 & 5.00 \\
\hline
\end{tabular}




\subsection{Proximate analysis}

The proximate analysis results of DPF samples are shown in Table 3 along with the reported results for selected coal samples and biomasses. The range of volatile matter content in DPF was found to be between 76 to $89 \%$; the highest volatile matter content was observed in Jeddah variety while the lowest was in Rothanah variety. The range was verified against those in Sukkari samples analyzed by Nasser et al and other in biomasses and was found to be in agreement with the published data. The significantly high content of volatile matter in DPF samples implies that they are highly suitable for pyrolysis and gasification processes, where the yields of solid to liquid and gas products through the thermal conversion processes may be more valuable than the heat it produces from direct incineration due to the combustion problems associated with biomass with high volatile content ${ }^{15}, 18$. The amount of fixed carbon in DPF samples was found to be comparatively lower than those in most biomasses. However, this observation is explained by the low amount of lignin component in DPF, which makes up for most of the fixed carbon in biomass fuel ${ }^{19}$. The ash content in DPF samples was found to be comparable with those in the featured biomasses, and was lower than those in peat, lignite and bituminous coals. This advantage makes DPF a highly appropriate fuel for continuous thermal processes, where ash removal and handling is a common technical barrier ${ }^{20}$.

\subsection{Thermal decomposition stages}

The temperature-dependent devolatilization stages for each DPF samples were identified based on TGA trends and DTGA peaks. Four thermal breakdown regions - 1st stage of active pyrolysis, 2nd stage of active pyrolysis, passive pyrolysis and char combustion - were identified. The identified stages of thermal breakdown of DPF are shown in Table 4. It was found that the 1 st active pyrolysis stage for all DPF samples began at around $141 \pm 4.5^{\circ} \mathrm{C}$, where light hydrocarbon components and traces of moisture were released. The 1st active pyrolysis stage progressed until the temperature reached around $325^{\circ} \mathrm{C}$ for all samples, where the 2nd active pyrolysis stage began, resulting to the initial release of heavier hydrocarbon compounds and liquid products such as pyrolysis oil and light tar. Passive pyrolysis began at above $500^{\circ} \mathrm{C}$ for all samples except for Rothanah and Jeddah varieties, where the stage began at $457^{\circ} \mathrm{C}$ and $478^{\circ} \mathrm{C}$ respectively, signifying the high reactivity of the sample against rising temperature. Heavier carbon aromatic compounds were released and broken at this stage as the temperature rose. The solid residue at this point in all samples was majorly made up of char, where it underwent combustion at temperatures above $600^{\circ} \mathrm{C}$ except for Rothanah at $552^{\circ} \mathrm{C}$. All samples were found to have lost half of their initial mass at around $320-340^{\circ} \mathrm{C}$, where the 2 nd stage active pyrolysis was ongoing, signifying that more than half of the tested DPF samples' mass was composed of hemicellulose and cellulose - the two most reactive natural polymeric fibers that break down at this particular thermal degradation stage. These findings were verified with the reported hemicellulose and cellulose content in Sukkari variety; hemicellulose content was reported to be between 43-45\% by weight, and cellulose content was in the range of $28-31 \%$ by weight ${ }^{9}$. The high reactivity of DPF samples at low temperatures releasing high amount of volatiles revealed their potentials for pyrolysis and low temperature gasification purposes.

Table 4. Thermal decomposition temperatures by stages for DPF samples

\begin{tabular}{|c|c|c|c|c|c|}
\hline \multirow{2}{*}{ DPF Sample } & \multicolumn{4}{|c|}{ Temperature, ${ }^{\circ} \mathbf{C}$} \\
\cline { 2 - 6 } & $\mathrm{T}_{1}$ & $\mathrm{~T}_{2}$ & $\mathrm{~T}_{3}$ & $\mathrm{~T}_{4}$ & $\mathrm{~T}_{\mathrm{hm}}$ \\
\hline Rothanah & 135.57 & 325.59 & 457.29 & 551.96 & 329.23 \\
\hline Jeddah & 138.24 & 329.41 & 478.11 & 637.21 & 322.41 \\
\hline Sukariah & 141.27 & 324.59 & 507.77 & 654.52 & 329.88 \\
\hline Ajwah & 147.11 & 327.86 & 515.41 & 681.71 & 333.14 \\
\hline Mishriq & 146.25 & 330.62 & 519.79 & 679.77 & 336.63 \\
\hline
\end{tabular}

$\mathrm{T}_{1}$ : initial $1{ }^{\mathrm{st}}$ phase active pyrolysis;

$\mathrm{T}_{2}$ : initial $2^{\text {nd }}$ phase active pyrolysis temperature;

$\mathrm{T}_{3}$ : initial passive pyrolysis temperature;

T4: char combustion temperature;

Thm: temperature where sample achieved half mass loss.

\section{Conclusions}

From the analysis results of DPF samples and in comparisons with the characteristics of selected low to medium rank coals and common biomass fuels, it was concluded that all DPF samples satisfied the typical requirements as solid fuel for thermal conversion processes in the heat and power generation sector. With its high and constant annual production amount, DPF has high potentials to be utilized as solid fuel for thermal applications in the Arab 
Peninsula and North African countries. The arid origins of DPF make its moisture removal faster, easier and cheaper through sun drying technique, all the more reasons to utilize the otherwise undervalued and underused residues as fuel materials. However, the processing aspect in terms of sizing and storage needs to be addressed in order to fully review DPF full potentials. Such investigation is therefore recommended for the progression of this study.

\section{References}

1. C.T. Chao, R.R. Krueger, Hort. Sci. 42 (5), 1077-1082 (2007)

2. FAO Statistics website (www.fao.org/faostat)

3. M. Shoaib, H.A. Al-Swaidan, Asian J. of Chem. 26 (20), 7025-7028 (2014)

4. A. Chehma, H. F. Longo, Rev. Energ. Ren. : Production et Valorisation - Biomasse, 59-64 (2001)

5. J. J. Pascual, C. Fernandez, J. R. Diaz, C. Garces, J.J Rubert-Aleman, Arid Environ. 45, 183-189 (2000)

6. S.A. Sulaiman, H.S. Bamufleh, S.N.A. Tamili, M. Inayat, M.Y. Naz, Bul. Chem. Soc. Ethiopia 30 (3), $465-$ $472(2016)$

7. A. Zaid, P.F. de Wet, Date Palm Cultivation (FAO, Rome, 2002)

8. Kalyani A. Motghare, Ajit P. Rathod, Kailas L. Wasewar, Nitin K. Labhsetwar, Waste Mgmt. 47 Part A, J 40-45 (2016)

9. R.A. Nasser, M.Z.M. Salem, S. Hiziriglu, H.A. Al-Mefarrej, A.S. Mohareb, M. Alam, I.M. Aref, Energies 9 (374) (2016)

10. M.D. Bispo, J.A.S. Barros, D. Tomasini, C. Primaz, E.B. Caramao. C. Dariva, L.C. Krause, J. Earth Sci. Eng. 6, 235-244 (2016)

11. FAO, Energy use of peat (http://www.fao.org/docrep/x5872e/x5872e0b.htm.)

12. A.G. Korotkokh, K.V. Slyusarskiy, K.B. Larionov, V.I. Osipov, J. Phy. Conference Series 754 (2016)

13. Y. Demirel, "Energy, energy types," in Green Energy, Technology (Springer-Verlag, London, 2012)

14. S.S. Abdullah, S. Yusup, J. App. Sci. 10 (24), 3301-3306 (2010)

15. B.M. Jenkins, L.L. Baxter, T.R. Miles Jr, T.R. Miles, Fuel Processing Tech. 54, 17-46 (1998)

16. A.E.D.M.M. Ibrahim, "NOx, SOx emissions, climate changes," World App. Sci. J. 31 (8), 1422-1426 (2014)

17. C. Bibbiani, F. Fantozzi, C. Gargari, C.A. Campiotti, E. Schettini, G. Vox, Agriculture, Agricultural Sci. Proc. 8, 637-645 (2016)

18. A.H. Tchapda, S.V. Pisupati, Energies 7, 1098-1148 (2014)

19. A. Demirbas, Energy Conv. \& Mgmt. 44 (9), 1481-1486 (2003)

20. Liang Wang, Johan E. Hustad, Øyvind Skreiberg, Geir Skjevrak, Morten Grønli, Energy Proc. 20, 20-29 (2012) 